\title{
Discussion: Road marking assessment using digital image
} analysis

\section{P. N. Burrow, H. T. Evdorides and M. S. Snaith}

S. Xavier, Highways Agency, Traffic Signs Team, Dorking Office, UK Grip testers are a problem with road markings with in-line road studs. They jump over them and disturb the computer software on board. It is an important point which needs an answer. This matter has been lying about unresolved for years.

\section{Authors' reply}

The interaction of grip testers, fitted to a data collection vehicle, with road studs may undoubtedly upset the correct functioning of computer hardware and software being used in such vehicles. However, as we have not investigated the use of grip testers in our work we are unfortunately unable to offer informed comment. 